\title{
Interannular Proton Exchange and Fragmentation of Carbonyl-protonated Benzophenones
}

Jing Sun and Hans-Friedrich Grützmacher*

Fakultät für Chemie der Universität Bielefeld, Postfach 8640, Universitätsstraße, D-4800 Bielefeld, Germany

Dedicated to Professor Dr G. Spiteller of Universität Bayreuth on the occasion of his 60th birthday

\begin{abstract}
Benzophenones $a$ initially protonated at the carbonyl group were prepared by electron-impact induced dissocation of 1,1-diphenylpropanols (compounds 1-5). These protonated ketones decompose in the ion source and the second field-free region of a reversed geometry mass spectrometer by proton migration to one of the phenyl groups and subsequent elimination of benzene. In the case of derivatives substituted by methoxy groups and trifluoromethyl groups, respectively, the proton migrates predominantly to the more basic benzene ring, resulting in the elimination of anisole in the former case and of benzene in the latter case. $A$ study of protonated benzophenones labelled at the phenyl ring and at the carbonyl group shows that only a few interannular H/D exchange steps precede the fragmentation. This is observed not only for metastable ions in the magnetic sector instrument but also for ions of long lifetimes investigated by Fourier-transform-ion cyclotron resonance (FT-ICR) spectrometry. This is in contrast to the arene elimination from protonated $1, \omega$-diphenylalkanes and related polyphenylalkanes which fragment by complete positional exchange of all hydrogen atoms at the aromatic rings. The special behaviour of protonated benzophenones is attributed to a low barrier for the decomposition of a chemically activated arenium ion $b$, which arises from the initial proton transfer. Once $b$ is formed, it decomposes quickly without much interannular proton exchange.
\end{abstract}

\section{INTRODUCTION}

Arenium ions, i.e. protonated aromatic species, are an interesting class of organic cations which have been intensively studied during the last few years. ${ }^{1}$ In the condensed phase, stable arenium ions are of great interest to chemists as reactive intermediates of important reactions of aromatic compounds. This refers primarily to the electrophilic aromatic substitution, ${ }^{2}$ but also to acid-catalysed transformations ${ }^{3}$ connected with the shifts of substituents in aromatic molecules (isomerization reactions) and with the intermolecular transfer of substituents.

In the gas phase, alkyl benzenium ions formed by chemical ionization fragment typically by dealkylation resulting in alkyl cations and benzene and by alkene elimination to form a protonated benzene. ${ }^{1 c, 4}$ Furthermore, gaseous arenium ions undergo proton rearrangement reactions both by intramolecular proton shifts and by intermolecular proton transfer. ${ }^{5}$ In particular, fast interannular proton exchanges are observed in protonated $\alpha, \omega$-diphenylalkanes ${ }^{5 f}$ even if the aromatic rings are separated by a long chain of $\mathrm{CH}_{2}$ units. A fast proton exchange occurs also in protonated tri- and tetra-benzylmethane, involving the 15 and 20 hydrogen atoms, respectively, at the phenyl groups and the additional proton. ${ }^{6}$ However, the proton exchange is suppressed in certain protonated diphenylcycloalkanes if the steric orientation of the phenyl groups prohibits a close contact between the aromatic groups. ${ }^{7}$ This confirms that the proton transfer between the aromatic moieties occurs by a direct transfer. For all these proto- nated polyphenylalkane derivatives, fragmentation occurs by the elimination of a neutral benzene molecule formally corresponding to a dealkylation process. The structures of the resulting ions are not known unambiguously, ${ }^{8}$ but the elimination of the benzene is very likely associated with a rearrangement to a stable fragment ion. ${ }^{5 e, 8}$

A reduced probability for the interannular proton exchange is also found in protonated diphenylmethane. ${ }^{9}$ In this case, the corresponding metastable ions exhibit only a few interannular exchange steps before loss of benzene. This divergent behaviour of protonated diphenylmethane as compared to its higher homologues may arise from some steric congestion in the transition state for the proton transfer in the absence of a long flexible link between the phenyl groups. However, the elimination of benzene from protonated diphenylmethane occurs by a direct dealkylation to a stable $\mathrm{C}_{7} \mathrm{H}_{7}{ }^{+}$ion and does not require necessarily a rearrangement. Therefore, the apparently slow proton exchange in protonated diphenylmethane preceding the benzene elimination may be in fact due to a more facile fragmentation of the parent ion. Consequently, ions of unusual low internal energy are sampled in the massanalysed ion kinetic energy (MIKE) spectrum which do not have enough energy to surmount an activation barrier of the interannular proton exchange. A considerable activation barrier is very likely present for the intramolecular proton transfer from a protonated carbonyl group to an aromatic ring. ${ }^{10}$ Furthmore, the bimolecular proton exchange between a benzenium ion and a benzene molecule is rather slow ${ }^{\text {sc }}$ indicating an activation barrier also for this process. In view of these 
results it is of interest to study in the gas phase the proton exchange and fragmentation of other protonated molecules, in which two phenyl groups are linked by a small group or atom, and which fragment by a direct loss of an arene molecule from the intermediate arenium ion. In this contribution we report on the mass spectrometric behaviour of protonated benzophenone and some of its substituted derivatives.

\section{RESULTS AND DISCUSSION}

Protonated benzophenone is most easily prepared in the gas phase by protonation of benzophenone in a suitable chemical ionization (CI) experiment. The carbonyl group of benzophenone is certainly the most basic site of the molecule (proton affinity (PA) (acetone) $=823 \quad \mathrm{~kJ} \mathrm{~mol}^{-1},{ }^{11} \quad P A$ (toluene) $=794 \mathrm{~kJ}$ $\mathrm{mol}^{-1,11} P A$ (benzophenone) $=882 \mathrm{~kJ} \mathrm{~mol}^{-1}{ }^{11}$ ), and consequently the most stable structure of protonated benzophenone corresponds to the diphenylhydroxymethyl cation $a$ (Scheme 1). However, depending on the reagent gas used for the CI experiment, a protonation at the phenyl groups may also occur, and in fact, the aromatic ring may be the most basic site of benzophenones substituted by electron donors (e.g. $\mathrm{CH}_{3} \mathrm{O}$ substituent, $P A($ anisole $\left.)=838 \mathrm{~kJ} \mathrm{~mol}^{-1}{ }^{11}\right)$. Hence, it is more convenient to prepare protonated benzophenones initially protonated at the carbonyl group by electronimpact induced fragmentation of suitable alkyldiphenylcarbinols. ${ }^{12}$ In this study ethyl-diphenylcarbinols 1-5 (Scheme 1) were used. The $70 \mathrm{eV}$ mass spectra of these compounds exhibit characteristically an intense signal for ions $\left[\mathrm{M}-\mathrm{C}_{2} \mathrm{H}_{5}\right]^{+}$corresponding to $a$, and large peaks due to benzoyl ions (Fig. 1 and Table 1). Metastable ions $a$ decompose by far predominantly by loss of a (substituted) benzene molecule.
This fragmentation is initiated by an intramolecular proton transfer from the carbonyl group to one of the aromatic rings generating a tautomer $b$ with the structure of a benzoyl benzenium ion. The occurrence of an endothermic proton transfer from a carbonyl group to the aromatic ring has been proven previously by the fragmentations of protonated aromatic ketones substituted by methoxymethyl groups. ${ }^{12,13}$ In the present case loss of a benzene is the only fragmentation energetically accessible. However, an interannular proton transfer between both aromatic group may precede this fragmentation and was studied by the fragmentations of suitable deuterated derivatives of $a$.

\section{Deuterated benzophenones}

The structures of the deuterated derivatives used in this study are shown in Scheme 2 . It is difficult to obtain the $70 \mathrm{eV}$ mass spectra of hydroxy compounds completely deuterated at the hydroxy group owing to the fast exchange with residual water in the ion source of the mass spectrometer. Hence, only the mass spectrum of 1-d $\mathbf{d}_{\mathbf{s}}$ fully deuterated at one phenyl group is reported in Fig. 1.

As expected, the $70 \mathrm{eV}$ EI mass spectrum of $1 \mathrm{a}-\mathbf{d}_{\mathbf{5}}$ exhibits two signals at $m / z \quad 110$ and $m / z \quad 105$ due to the loss of $\mathrm{C}_{6} \mathrm{H}_{6}$ and $\mathrm{C}_{6} \mathrm{HD}_{5}$, respectively, but additionally also a small peak at $\mathrm{m} / z 109\left(\right.$ loss of $\left.\mathrm{C}_{6} \mathrm{H}_{5} \mathrm{D}\right)$. This indicates some $H / D$ exchange between the two aromatic rings of $1 \mathrm{a}-\boldsymbol{d}_{5}$, but clearly excludes a fast and complete interannular $\mathrm{H} / \mathrm{D}$ exchange for the ions decomposing in the ion source. Interestingly the loss of $\mathrm{C}_{6} \mathrm{HD}_{5}(\mathrm{~m} / \mathrm{z}$ 105 ) is more intense than the combined abundances for the losses of $\mathrm{C}_{6} \mathrm{H}_{6}$ and $\mathrm{C}_{6} \mathrm{H}_{5} \mathrm{D}$ (ratio 52.8/47.2) corresponding to an isotope effect of 0.89 and showing apparently a preferred initial migration of the proton

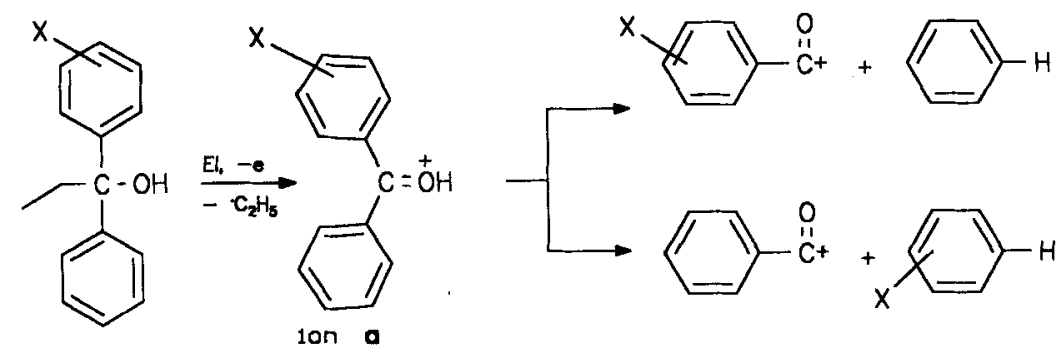

$$
\begin{array}{c|ccccc}
x & \mathrm{H} & \mathrm{P}-\mathrm{OCH}_{3} & \mathrm{~m}-\mathrm{OCH}_{3} & \mathrm{p}-\mathrm{CF}_{3} & \mathrm{~m}-\mathrm{CF}_{3} \\
\hline 1 & 2 & 3 & 4 & 8
\end{array}
$$

Scheme 1

Table 1. Characteristic ions in the $70 \mathrm{eV}$ mass spectra of the ethyl diphenyl carbinols (1-5)

\begin{tabular}{|c|c|c|c|c|c|c|c|c|c|c|}
\hline \multirow[b]{2}{*}{ Ion } & \multicolumn{2}{|c|}{1} & \multicolumn{2}{|c|}{2} & \multicolumn{2}{|c|}{3} & \multicolumn{2}{|c|}{4} & \multicolumn{2}{|c|}{5} \\
\hline & $m / z$ & $\%$ & $m / 2$ & $\%$ & $m / 2$ & $\%$ & $m / 2$ & $\%$ & $m / z$ & $\%$ \\
\hline $\mathrm{M}^{+\bullet}$ & 212 & 0.4 & 242 & 2.9 & 242 & 0.9 & 280 & 0.2 & 280 & 0.2 \\
\hline $\mathrm{M}^{+\cdot}-\mathrm{H}_{2} \mathrm{O}$ & 194 & 0.5 & 224 & 1.8 & 224 & 0.9 & & & & \\
\hline$a$ & 183 & 100 & 213 & 100 & 213 & 89 & 251 & 100 & 251 & 100 \\
\hline$a-\mathrm{C}_{6} \mathrm{H}_{6}$ & 105 & 83 & 135 & 29 & 135 & 15 & 173 & 45 & 173 & 63 \\
\hline$a-\mathrm{C}_{6} \mathrm{H}_{5} \mathrm{X}$ & & & 105 & 42 & 105 & 100 & 105 & 20 & 105 & 15 \\
\hline $\mathrm{C}_{6} \mathrm{H}_{4} \mathrm{X}^{+\cdot}$ & & & 107 & 3 & 107 & 5 & 145 & 22 & 145 & 19 \\
\hline $\mathrm{C}_{6} \mathrm{H}_{5}^{+*}$ & 77 & 47 & 77 & 26 & 77 & 31 & 77 & 14 & 77 & 12 \\
\hline
\end{tabular}


<smiles>CCC(O)(c1ccccc1)c1ccccc1</smiles><smiles>CCC(O)(c1ccccc1)c1ccc(C)cc1</smiles>

1(OD)

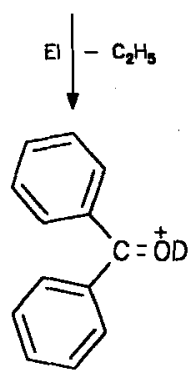

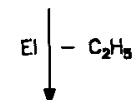<smiles>O=C(c1ccccc1)c1ccccc1</smiles>

$$
\text { o-do }
$$

Scheme 2

a(OD)<smiles>CCC(O)(O)c1ccccc1</smiles><smiles>[13CH][13CH3]</smiles><smiles>[Te]=C(c1ccccc1)c1ccccc1</smiles>

a-dof(OD)

from the carbonyl group to the $C_{6} D_{5}$ group. More details of the interannular proton migration in ions $a$ result from a study of the decompositions of isotopomers of metastable $a$, and from their reactions at even longer life times investigated by ICR experiments.

Table 2. MIKE spectra of $a$ and its deuterated analogues

\begin{tabular}{ccccc}
$m / 2$ & $d$ & $\theta(00)$ & $a-d_{s}$ & $d-d_{5}(00)$ \\
105 & 100 & 71.4 & 47.4 & 39.7 \\
106 & & 28.6 & & 11.0 \\
109 & & & 10.1 & \\
110 & & & 42.5 & 49.2 \\
\hline
\end{tabular}

The MIKE and collisional activation (CA) spectra of these deuterated ions are shown in Table 2. The MIKE spectrum of $a-\mathrm{OD}$, corresponding to a carbonyldeuteronated benzophenone, exhibits signals for the loss of $\mathrm{C}_{6} \mathrm{H}_{5} \mathrm{D}$ and $\mathrm{C}_{6} \mathrm{H}_{6}$, the latter requiring an interannular $\mathrm{H} / \mathrm{D}$ exchange after the initial $\mathrm{D}^{+}$migration to one of the phenyl groups (Scheme 3). Similarly, the MIKE spectrum of $a-d_{5}$ reveals some H/D-exchange by a small peak owing to the loss of $\mathrm{C}_{6} \mathrm{H}_{5} \mathrm{D}$ besides those for the elimination of $\mathrm{C}_{6} \mathrm{H}_{6}$ and $\mathrm{C}_{6} \mathrm{HD}_{5}$. Finally, the MIKE spectrum of $a-d_{5}(\mathrm{OD})$ contains a signal for the loss of $\mathrm{C}_{6} \mathrm{HD}_{5}$ which again has to arise from an interannular proton transfer. However, in all spectra the relative abundances of the signals indicating the H/D exchange are small, and the ratio of the abundances for the loss of the isotopomers $\mathrm{C}_{6} \mathrm{H}_{6-x} \mathrm{D}_{x}$ are far from those calculated for a statistical distribution of the label
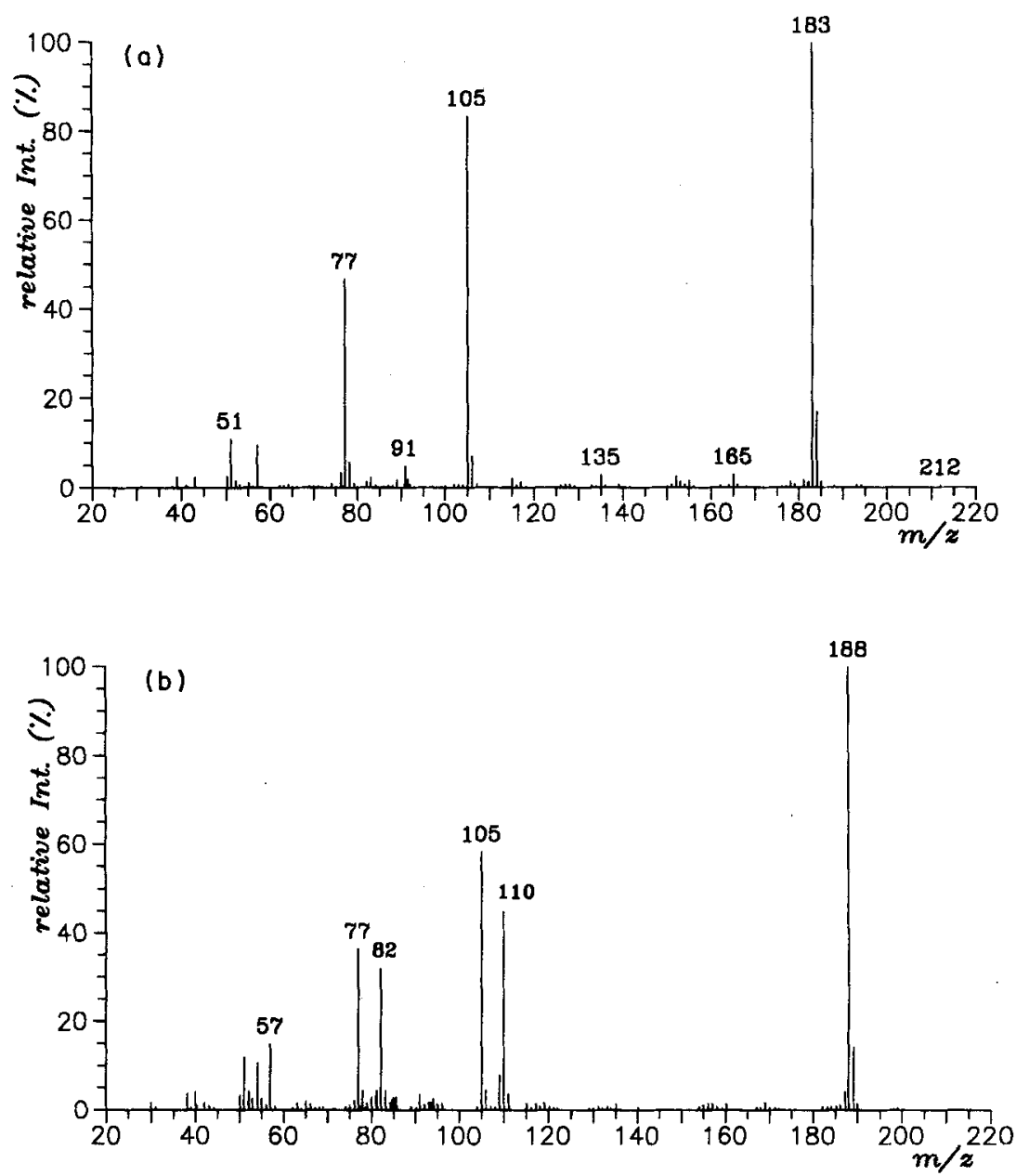

Figure 1. $70 \mathrm{eV}$ mass spectra of (a) 1,1-diphenylpropanol $\left(1, M^{+\cdot}\right.$ 212) and (b) 1-pentadeuterophenyl-1-phenylpropanol (1-d,$M^{+\cdot}$ 217). 


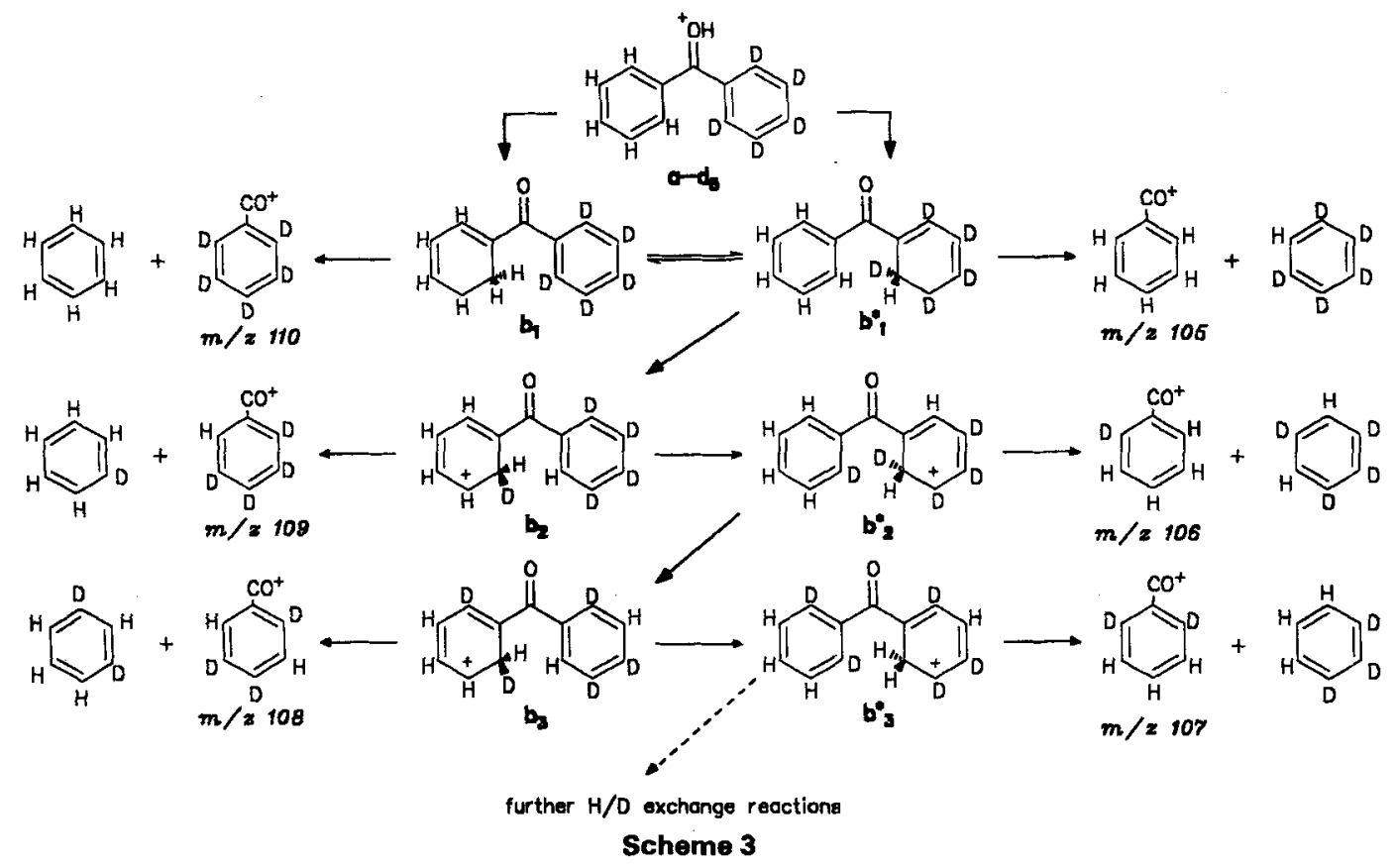

prior to the fragmentation. In the latter two cases no signals due to an exchange of more than one $H$ or $D$ atom by several reversible interannular transfer steps are detected. Hence, protonated benzophenone $a$ suffers in the average less than one interannular proton transfer step within the lifetime of metastable ions in a VG ZAB-2F mass spectrometer $(\sim 10 \mu \mathrm{s})$.

In passing, one notes that contrary to the decompositions in the ion source, the relative abundance for the loss of $\mathrm{C}_{6} \mathrm{HD}_{5}$ from metastable $a-d_{5}$ is less than for the loss of $\mathrm{C}_{6} \mathrm{H}_{6}$ and $\mathrm{C}_{6} \mathrm{H}_{5} \mathrm{D}$ (ratio $\left[-\left(\mathrm{C}_{6} \mathrm{H}_{6}+\mathrm{C}_{5} \mathrm{H}_{5} \mathrm{D}\right.\right.$ )/ $\left.-\mathrm{C}_{6} \mathrm{HD}_{5}\right]=1.11$ ). Thus, the (net) isotope effect for the benzene elimination is reversed for the metastable ions, and its direction depends strongly on the internal energy of the decomposing ion. The observed isotope effects result obviously from a complicated amalgamation of $H / D$ isotope effects for the individual reaction steps: (i) a secondary isotope effect for the initial migration of $\mathrm{H}^{+}$from the carbonyl group to either $\mathrm{C}_{6} \mathrm{H}_{5}$ or $\mathrm{C}_{6} \mathrm{D}_{5}$; (ii) a primary isotope effect for intra- and interannular $\mathrm{H} / \mathrm{D}$ migration; (iii) a secondary isotope effect for the eventual loss of benzene isotopomers. The available experimental data do not allow the separation of these contributions to the isotope effect.

The CA spectra of $a$ and its isotopomers $a-d_{5}$ and $a-d_{5}(\mathrm{OD})$ are shown in Table 3 . The most intense signal in the spectrum of $a$ at $m / z \quad 105$ is still due to the benzene elimination but another abundant fragment ion is the phenyl cation, $m / z$ 77. Each of these signals is split into two peaks at $m / z 77$ and $m / z \quad 82$ and $m / z \quad 105$ and $m / z 110$, respectively, in the spectrum of $a-d_{5}$. The mass resolution of the CA spectra is too low to resolve any small peaks due to H/D exchange (however, see below for the ICR spectra). Nevertheless, the relative abundance of the loss of $\mathrm{C}_{6} \mathrm{HD}_{5}$ has increased and the ratio $-\mathrm{C}_{6} \mathrm{H}_{6} /-\mathrm{C}_{6} \mathrm{HD}_{6}=0.87$ is nearly identical to that found in the $70 \mathrm{eV}$ mass spectrum. These results referring to the reactions of protonated benzophenone within $10 \mu$ s or less show clearly that an interannular $H$ migration subsequent to the proton transfer from the carbonyl group to the aromatic rings is slow and does not effectively compete with the fragmentation yielding the stable benzoyl cation.

The H/D exchange in protonated benzophenones $a$ at much longer reaction times was studied by ion cyclotron resonance (ICR) spectrometry. Ions $a-d_{5}$ were generated from $1-d_{5}$ by electron-impact induced dissociation in the external ion source and transferred into the ICR cell. The ions $a-d_{5}$ thus obtained in the

\begin{tabular}{|c|c|c|c|}
\hline \multirow{2}{*}{$\begin{array}{c}\text { Table } \\
m / z\end{array}$} & \multicolumn{3}{|c|}{$\begin{array}{l}\text { CA spectra of a and } \\
\text { some deuterated ana- } \\
\text { logues }\end{array}$} \\
\hline & CA & $\begin{array}{l}a-d_{3} \\
C A\end{array}$ & $\begin{array}{c}a-d_{g}(O D) \\
C A\end{array}$ \\
\hline $\begin{array}{l}51 \\
53\end{array}$ & $\begin{array}{r}10.1 \\
3.0\end{array}$ & 4.8 & 6.3 \\
\hline 54 & & 6.7 & 7.7 \\
\hline 63 & 4.7 & 1.9 & 2.9 \\
\hline 65 & 1.4 & 1.9 & 2.3 \\
\hline 77 & 25.6 & 21.7 & 16.4 \\
\hline 78 & & & 2.2 \\
\hline 79 & & 12.1 & 12.3 \\
\hline 105 & 38.2 & 21.7 & 16.4 \\
\hline 106 & & & 3.2 \\
\hline 109 & & & \\
\hline 110 & & 18.9 & 16.9 \\
\hline 114 & 1.7 & & \\
\hline 118 & & 2.0 & 1.9 \\
\hline 126 & 1.6 & & \\
\hline 130 & & 2.2 & \\
\hline 131 & & & 1.9 \\
\hline 152 & 6.3 & & \\
\hline 156 & & 5.3 & 5.9 \\
\hline 165 & 1.7 & & \\
\hline 169 & & 0.7 & \\
\hline 170 & & 0.7 & 2.0 \\
\hline 181 & 1.9 & & \\
\hline 182 & 2.6 & & \\
\hline 186 & & 1.5 & 1.0 \\
\hline 187 & & 1.9 & 1.6 \\
\hline 188 & & & 2.0 \\
\hline
\end{tabular}




\begin{tabular}{|c|c|c|c|c|}
\hline \multirow[b]{2}{*}{$m / z$} & \multicolumn{4}{|c|}{ Reaction time } \\
\hline & $0.001 \mathrm{~s}$ & $0.5 \mathrm{~s}$ & $1.0 \mathrm{~s}$ & $5.0 \mathrm{~s}$ \\
\hline 77 & 1.5 & 1.5 & 1.7 & 0.8 \\
\hline 78 & 0.3 & 0.4 & 0.4 & \\
\hline 81 & 0.7 & 0.7 & 0.7 & 0.3 \\
\hline 82 & 1.2 & 1.2 & 1.2 & 0.6 \\
\hline 105 & 26.4 & 26.3 & 26.1 & 28.5 \\
\hline 106 & 6.0 & 5.8 & 5.6 & 6.4 \\
\hline 107 & 1.4 & 1.4 & 1.3 & 1.0 \\
\hline 108 & 3.0 & 2.7 & 0.8 & 2.1 \\
\hline 109 & 9.5 & 9.1 & 8.8 & 9.7 \\
\hline 110 & 20.6 & 20.4 & 31.2 & 27.5 \\
\hline 118 & 29.4 & 30.5 & 31.2 & 27.5 \\
\hline $110 / 109$ & 2.16 & 2.25 & 2.30 & 2.37 \\
\hline
\end{tabular}

ICR cell are stable with respect to any further spontaneous decomposition. The ions fragment, however, by collisional activation after introducing argon into the ICR cell and exciting the ions kinetically by an appropriate rf pulse.

To detect any slow interannular H/D-exchange within these ions two types of experiments were performed. In the first series of experiments the collisioninduced decomposition of the ions were achieved by a constant kinetic excitation by a rf pulse of constant amplitude and duration (8-9 $\mu \mathrm{s})$, but after varying the reaction time between isolation and excitation of the ions from 0.001 to $5.0 \mathrm{~s}$. Thus, any slow interannular H/D exchange will give rise to the elimination of the benzene isotopomers $\mathrm{C}_{6} \mathrm{H}_{6-x} \mathrm{D}_{x}(x=1-4)$ increasing with reaction time. In the second series of experiments, the reaction time before the collision-induced decomposition was kept constant, but the kinetic excitation of the ions was increased by increasing the duration of the rf pulse for the acceleration of the ions from $8 \mu$ s to 20 $\mu s$. Thus, the ions in the ICR cell accumulate more kinetic energy, which can be used for collision-induced decompositions, and any dependence of the interannular $H / D$ exchange on the internal energy of the ions $a-d_{5}$ during the decomposition should be observed.
The results for both experiments are presented in Tables 4 and 5 , respectively.

Under the conditions of the first series of experiments (Table 4) about $70 \%$ of the ions $a-d_{5}$ decompose mainly by benzene loss. The much better resolution of the ICR spectrometer (and the investigation of a pure ${ }^{12} \mathrm{C}$ species!) allows clearly the observation of signals due to the elimination of all possible isotopomers $\mathrm{C}_{6} \mathrm{H}_{6-x} \mathrm{D}_{x}$. However, the relative abundances are again far from the values for a statistical distribution of the labels prior to the decomposition. More important, the peak patterns in these CA spectra of long-lived ions $a-d_{5}$ are independent of the reaction time preceding the collisional activation. Thus, the small extent of $H / D$ exchange observed for $a-d_{5}$ in the $70 \mathrm{eV}$ EI mass spectra as well as in the MIKE spectra and the CA spectra obtained by the ICR technique is not due to a slow continuous process but must have occurred either before the formation of $a-d_{5}$ by electron-impact induced dissociation of $1-d_{5}$, or during the further decomposition of activated $a-d_{5}$.

This latter possibility has been tested in the second type of experiment by varying the amount of energy transferred to stable $a-d_{5}$ during collisional activation. The increase of the collision energy is clearly seen from the values in Table 5 by the decrease of the relative abundance of the parent ion $a-d_{5}$ and the increasing intensities of low-mass fragment ions. However, a nearly constant degree of $H / D$ exchange independent of the collision energy of the precursor ions is observed. ${ }^{14}$ The most likely explanation for the invariance of the amount of H/D exchange of the ions $a-d_{5}$ with respect to lifetimes spanning from microseconds (MIKE spectrum) to seconds (ICR-CA spectrum) is an H/D exchange occurring in competition with the fragmentation of a chemically activated species protonated at the aromatic ring.

The proton transfer from the carbonyl group to the aromatic ring of $a$ is endothermic and MNDO calculations have shown ${ }^{10}$ that this transfer needs additional activation energy. Hence, the benzenium ion $b$ is always formed (from $a$ ) with a considerable amount of free internal energy. This excess energy is used either for a

Table 5. FT-ICR spectra of $a-d_{5}$. Effect of collision energy on the $H / D$ exchange (collision gas argon)

\begin{tabular}{rrrrrrrrr} 
& & \multicolumn{7}{c}{ Excitation time of parent ion $\mathrm{a}-d_{\mathrm{s}}$} \\
$m / z$ & $0 \mu \mathrm{s}$ & $8 \mu \mathrm{s}$ & $10 \mu \mathrm{s}$ & $12 \mu \mathrm{s}$ & $14 \mu \mathrm{s}$ & $16 \mu \mathrm{s}$ & $18 \mu \mathrm{s}$ & $20 \mu \mathrm{s}$ \\
51 & & & & & 1.3 & 3.0 & 5.1 & 8.0 \\
54 & & & & & 1.4 & 3.4 & 5.8 & 8.0 \\
77 & & 1.2 & 3.1 & 6.0 & 9.6 & 13.1 & 15.7 & 17.3 \\
78 & & & & 0.8 & 1.4 & 1.8 & 2.2 & 2.2 \\
81 & & 0.5 & 1.2 & 1.9 & 3.0 & 3.8 & 4.2 & 4.6 \\
82 & & 0.9 & 2.6 & 5.1 & 8.7 & 11.6 & 14.0 & 14.7 \\
105 & 3.9 & 9.8 & 14.2 & 15.9 & 15.8 & 16.0 & 14.1 & 12.7 \\
106 & 1.4 & 3.3 & 4.1 & 4.6 & 4.6 & 4.2 & 3.8 & 3.6 \\
107 & & & & & & & & \\
108 & 0.4 & 0.8 & 1.3 & 1.2 & 1.2 & 1.3 & & \\
109 & 2.6 & 6.1 & 7.7 & 8.1 & 8.9 & 8.0 & 7.5 & 6.4 \\
110 & 2.5 & 6.7 & 10.0 & 11.5 & 11.2 & 11.2 & 10.0 & 9.1 \\
188 & 96.0 & 70.6 & 56.0 & 44.7 & 32.7 & 23.4 & 17.4 & 12.0 \\
$110 / 109$ & 0.96 & 1.10 & 1.30 & 1.42 & 1.26 & 1.39 & 1.32 & 1.42 \\
\hline
\end{tabular}


proton transfer between the two phenyl groups or for a protiolysis of the bond to the carbonyl group and the release of a benzoyl cation. Obviously, the 'direct' bond cleavage yielding the stable benzoyl cation is favoured entropically and limits the life time of isomer $b$ to a short interval excluding a substantial H/D exchange by multi-step proton or deuteron transfer between the aromatic rings (Scheme 3). According to this mechanism, the ions $a$ observed in the MIKE spectra are not metastable because of a slow fragmentation but because of a slow proton transfer from the carbonyl group to the benzene ring. Once the isomer $b$ is formed, it decomposes quickly because of this chemical activation. In fact, the loss of benzene from $a$ (or $b$ ) gives rise to a broad Gaussian-shaped peak in the MIKE spectrum. A kinetic energy release (KER) of $192 \mathrm{meV}$ has been calculated from the width of the peak at $50 \%$ intensity. This is a rather larger KER for a direct bond cleavage and shows clearly that an energy and rate determining step precedes the formation of the benzoyl cations from $a$, as required by the mechanism proposed.

\section{Substituted benzophenones}

The ethyl diphenylcarbinols (2-5), substituted at only one of the phenyl rings, give rise to unsymmetrically substituted protonated benzophenones by electronimpact induced dissociation. The further decomposition of these substituted derivatives of $a$ by proton migration from the carbonyl group and loss of an arene molecule may occur in principle by loss of $\mathrm{C}_{6} \mathrm{H}_{6}$ and $\mathrm{C}_{6} \mathrm{H}_{5} \mathrm{X}$ $\left(\mathrm{X}=\mathrm{OCH}_{3}, \mathrm{CF}_{3}\right)$, respectively, giving rise to a substituted benzoyl cation $\mathrm{X}-\mathrm{C}_{6} \mathrm{H}_{4} \mathrm{CO}^{+}\left(\mathrm{X}=\mathrm{CH}_{3} \mathrm{O}, \mathrm{m} / \mathrm{z}\right.$ 135; $\mathrm{X}=\mathrm{CF}_{3} ; \mathrm{m} / z$ 173) or the benzoyl cation $\mathrm{C}_{6} \mathrm{H}_{5} \mathrm{CO}^{+}, \mathrm{m} / \mathrm{z}$ 105. Indeed. Table 1 shows that both fragmentations are observed for the ions decomposing in the ion source, but with different probability. In the case of the $\mathrm{CH}_{3} \mathrm{O}$ substituent ( 2 and 3 ) the loss of anisole and formation of the unsubstituted benzoyl cation is favoured especially for the meta-isomer 3, while in the case of a $\mathrm{CF}_{3}$ substituent ( 4 and 5) benzene is lost preferentially and the substituent is retained in the benzoyl cation. The same influence of the substituent is observed even more definitely in the MIKE spectra of the substituted ions $a$ (Table 6). The $\mathrm{CH}_{3} \mathrm{O}$ substituted ions $a\left(p-\mathrm{OCH}_{3}\right)$ and $a\left(m-\mathrm{OCH}_{3}\right)$ eliminate predominantly anisole in particular in the case of metasubstitution while $\mathrm{CF}_{3}$ substitution in $a\left(p-\mathrm{CF}_{3}\right)$ and
$a\left(m-\mathrm{CF}_{3}\right)$ leads to preferred loss of benzene but without a distinct positional effect.

Obviously, the initial proton migration from the carbonyl group to the more basic aromatic ring determines the fragmentation for high-energy ions reacting in the ion source as well as for metastable ions. This is compatible with only insignificant hydrogen migration between the substituted and unsubstituted phenyl groups, and is confirmed by the fragmentation of deuterated analogues of the substituted ions $a$. The MIKE spectra of $a\left(p-C_{3}\right)(\mathrm{OD})$ and $a\left(m-\mathrm{CF}_{3}\right)(\mathrm{OD})$ contain signals of $\mathrm{CF}_{3} \mathrm{C}_{6} \mathrm{H}_{4} \mathrm{CO}^{+}$and $\mathrm{CF}_{3} \mathrm{C}_{6} \mathrm{H}_{3} \mathrm{DCO}^{+}$at $\mathrm{m} / z$ 173 and $m / z 174$, respectively, in the ratio $100: 8$. The small signal of the benzoyl cation, however, is split into signals for $\mathrm{C}_{6} \mathrm{H}_{5} \mathrm{CO}^{+}, \mathrm{m} / z 105$ and $\mathrm{C}_{6} \mathrm{H}_{4} \mathrm{DCO}^{+}, \mathrm{m} / \mathrm{z}$ 106 , in a ratio of approximately $1: 1$. Obviously, the few metastable ions of higher internal energy fragmenting by this process suffer more $H / D$ exchanges. The methoxy substituted derivatives behave somewhat differently. In the case of the deuterated derivatives of ion $a\left(p-\mathrm{OCH}_{3}\right)$, the $\mathrm{H} / \mathrm{D}$ exchange observed during the formation of the benzoyl cation by the low-energy route corresponds approximately to the exchange in $a$. However, no $H / D$ exchange accompanies the formation of the para-methoxybenzoyl cation by the high-energy route. In contrast, the formation of the benzoyl cation from the meta-methoxy derivatives $a\left(m-\mathrm{OCH}_{3}\right)(\mathrm{OD})$, $a\left(m-\mathrm{OCH}_{3}\right) d_{5}$ and $a\left(m-\mathrm{OCH}_{3}\right) d_{5}(\mathrm{OD})$ occurs without $H / D$ exchange, whereas the peak of the metamethoxybenzoyl cation, $m / z 135$, is completely shifted to $m / z 136$ in the MIKE spectra of $a\left(m-\mathrm{OCH}_{3}\right)(\mathrm{OD})$ and $a\left(m-\mathrm{OCH}_{3}\right) d_{5}(\mathrm{OD})$. This difference between the positional isomers $a\left(p-\mathrm{OCH}_{3}\right)$ and $a\left(m-\mathrm{OCH}_{3}\right)$ probably indicates a migration of the proton from the carbonyl group to the ortho-position of the methoxylated ring of the meta-isomer. This position exhibits an especially large local proton affinity due to its para-orientation to the methoxy substituent. Hence, the proton (deuteron) transferred to this position tends to stay there, and no $H / D$ exchange is observed during the further fragmentations.

\section{EXPERIMENTAL}

\section{Mass spectrometry}

The EI mass spectra of 1-5 and their deuterated derivatives were obtained with a MAT $\mathrm{CH}_{5}$ mass spectro-

Table 6. MIKE spectra of substituted $a$ and some deuterated derivatives

\begin{tabular}{lrlllllll}
\multicolumn{1}{c}{$m / \mathbf{z}$} & 105 & 106 & 109 & 110 & 135 & 136 & 173 & 174 \\
$a(p-\mathrm{OMe})$ & 100 & & & & 20 & & & \\
$a(p-\mathrm{OMe})(\mathrm{OD})$ & 100 & 30 & & & 20 & & & \\
$a(p-\mathrm{OMe})-d_{5}$ & & & 15 & 100 & 30 & & & \\
$a(m-\mathrm{OMe})$ & 100 & & & & 6 & & & \\
$a(m-\mathrm{OMe})(\mathrm{OD})$ & 100 & & & & & 6 & & \\
$a(m-\mathrm{OMe})-d_{5}$ & & & & 100 & 8 & & & \\
$a(m-\mathrm{OMe})-d_{5}(\mathrm{OD})$ & & & & 100 & & 5 & & \\
$a\left(p-\mathrm{CF}_{3}\right)$ & 4 & & & & & & 100 & \\
$a\left(p-\mathrm{CF}_{3}\right)(\mathrm{OD})$ & 2 & 2 & & & & & 100 & 8 \\
$a\left(m-\mathrm{CF}_{3}\right)$ & 3 & & & & & & 100 & \\
$a\left(m-\mathrm{CF}_{3}\right)(\mathrm{OD})$ & 2 & 2 & & & & & 100 & 8 \\
\hline
\end{tabular}


meter under the following conditions: electron energy $70 \mathrm{eV}$; ion source temperature $\sim 180^{\circ} \mathrm{C}$; accelerating voltage $3 \mathrm{kV}$, introduction of the samples at ambient temperatures by direct insertion probe; recording of the spectra by a Technivent data system. The MIKE spectra were recorded with a VG ZAB-2F mass spectrometer using the following conditions: electron energy $70 \mathrm{eV}$, ion source temperature $\sim 180^{\circ} \mathrm{C}$, accelerating voltage $6 \mathrm{kV}$, sample introduction by a homebuilt direct inlet system at $100^{\circ} \mathrm{C}$. The ions $a$ generated in the ion source were focused magnetically into the second fieldfree region after the magnet and the metastable ion spectra were recorded by scanning the deflecting voltage of the electrostatic analyser. The CA spectra were obtained by the same technique but introducing $\mathrm{He}$ as collision gas into the collision cell of the second fieldfree region at such a rate, that the intensity of the main beam was attenuated to $\sim 30 \%$. The $H / D$ exchange at long life times was studied with a Bruker Spectrospin FT-ICR spectrometer. The ions were generated in the external ion source by electron-impact ionization with $70 \mathrm{eV}$ electrons and the ions transferred into the ICR cell at a background pressure of $1-2 \times 10^{-9}$ mbar. The deuterated analogues of ion $a$ were isolated by broadband ejection of most ions and a series of 'single shots' exciting ion specifically at neighbouring $m / z$ values to the ions $a$. For the further procedure see above.

\section{Compounds}

All compounds were prepared and purified by standard methods of organic chemistry. The correct structure was established by ${ }^{1} \mathrm{H}-\mathrm{NMR}$ and the purity controlled by chromatographic methods.

1,1-Diphenylpropanol (1) was prepared by reaction of propiophenone $(0.1 \mathrm{~mol})$ with phenylmagnesium bromide $(0.1 \mathrm{~mol})$ in ether; yield $71 \%$. 1-(p-Methoxyphenyl)-1-phenylpropanol (2) was obtained by the same method using propiophenone $(0.22 \mathrm{~mol})$ and $p$ methoxyphenylmagnesium bromide $(0.22 \mathrm{~mol})$; yield 54\%. 1-(m-Methoxyphenyl)-1-phenylpropanol (3) was synthesized using propiophenone $(0.47 \mathrm{~mol})$ and $\mathrm{m}$ methoxyphenylmagnesium bromide $(0.5 \mathrm{~mol})$; yield 40\%. 1-(p-Trifluoromethylphenyl)-1-phenylpropanol (4) was prepared by reaction of p-trifluoromethylbenzophenone $(0.9 \mathrm{mmol})$ with ethylmagnesium bromide; yield $\quad 39 \%$. 1-(m-Trifluoromethylphenyl)-1-phenylpropanol (5) was obtained similarly from p-trifluoromethylbenzophenone $(8 \mathrm{mmol})$ and ethylmagnesium bromide; yield $45 \%$.

\section{Deuterated compounds}

The derivatives deuterated at the hydroxyl group were prepared by several exchanges with $\mathrm{D}_{2} \mathrm{O}$ and conditioning of the inlet system and the ion-source region of the VG ZAB-2F mass spectrometer with $\mathrm{D}_{2} \mathrm{O}$ prior to the measurement. 1-Phenyl-1- pentadeuterophenylpropanol $\left(1-d_{5}\right), \quad 1-(p-m e t h o x y p h e n y l)-1$-pentadeuterophenylpropanol (2-d $\left.d_{s}\right)$ and 1-(m-methoxyphenyl-1-pentadeuterophenylpropanol were synthesized from the respective propiophenone and pentadeuterophenylmagnesium bromide. D-contents (by mass spectrometry, calculated from the peak $\left[\mathrm{M}-\mathrm{C}_{2} \mathrm{H}_{5}\right]^{+}$) 1-d $d_{5}: d_{5} 96.1 \%, d_{4} 3.9 \%$; $2-d_{5}: d_{5} 96.8 \%, d_{4} 3.2 \% ; 3-d_{5}: d_{5} 95.9 \%, d_{4} 4.1 \%$.

\section{Acknowledgements}

The FT-ICR spectrometer used was a gift from the Deutsche Forschungsgemeinschaft, which is gratefully acknowledged. We thank the Fonds der Chemischen Industrie for financial assistance of this work.

\section{REFERENCES}

1. (a) P. Ahlberg, G. Tonsöll and C. Engdahl, Adv. Phys. Org. Chem. 19, 313 (1983); (b) V. A. Koptyug, Top. Curr. Chem. 122, 1 (1984); (c) D. Kuck, Mass Spectrom. Rev. 9, 583 (1990).

2. (a) R. Taylor in Organic Reaction Mechanism, Chem. Soc Special Publication No. 19 (Ed. by C. H. Bamford and C. F. H. Tipper), Amsterdam (1972); (b) G. A. Olah and Y. K. Mo in Carbonium lons (Ed. by G. A. Olah and P. von R. Schleyer) Vol. V, p. 2135, Wiley, New York (1976).

3. H. J. Shine in Reaction Mechanism in Organic Chemistry (Ed. by C. Eaborn and N. B. Chapman) Vol. 6 Aromatic Rearrangements, Elsevier, Amsterdam (1967).

4. (a) M. S. B. Munson and F. H. Field, J. Am. Chem. Soc. 89 , 1047 (1967); (b) H. W. Leung and A. G. Harrison, Org. Mass Spectrom. 12582 (1977): (c) J. A. Herman and A. G. Harrison, Org. Mass Spectrom. 16, 423 (1981); (d) R. W. Holman and M. L. Gross, J. Am. Chem. Soc. 111, 3560 (1989).

5. (a) A. P. Bruins and N. M. M. Nibbering, Org. Mass Spectrom. 11, 950 (1976); (b) D. Kuck, W. Bäther and H.-Fr. Grützmacher, J. Am. Chem. Soc. 101, 7154 (1979); (c) D. Kuck H.-Fr. Grützmacher, S. Ingeman, L. de Koning and N. M. M. Nibbering, Angew. Chem. 97, 691 (1985); Angew. Chem. Int. Ed. Engl., 24, 693 (1985), (d) W. Bather, D. Kuck and H.-Fr. Grützmacher; Org. Mass Spectrom. 20, 589 (1985); (e) W. Bäther and H.-Fr. Grützmacher, Int. J. Mass Spectrom. Ion Processes, 64, 193 (1985); (f) D. Kuck, W. Băther and H.-Fr.
Grützmacher, Int. J. Mass Spectrom. Ion Processes, 67, 75 (1985).

6. D. Kuck, Int. J. Mass Spectrom. Ion Phys. 47, 499 (1983),

7. D. Kuck, D. Thölmann and H.-Fr. Grützmacher, J. Chem. Soc., Perkin Trans., 251 (1990).

8. D. Kuck and U. Fastabend, Adv. Mass Spectrom. 11A, 904 (1989).

9. D. Kuck and W. Bäther, Org. Mass Spectrom. 21, 451 (1986)

10. U. Filges and H.-Fr. Grutzmacher, Int. J. Mass Spectrom. Ion Processes, 83, 93 (1988)

11. S. G. Lias, J. E. Bartmess, J. F. Liebman, J. L. Holmes, R. Levin and W. G. Mallard, J. Phys. Chem. Ref. Data, 17, Suppl. 1 (1988).

12. H.-Fr. Grützmacher, G. Thielking, D. Wittneben and D. Eikenberg, Int. J. Mass Spectrom. Ion Processes, 98, 259 (1990).

13. (a) U. Filges and H.-Fr. Grützmacher, Org. Mass Spectrom. 21, 673 (1986); (b) U. Filges and H.-Fr. Grützmacher, Org. Mass Spectrom. 22, 444 (1987); (c) U. Filges and H.-Fr. Grützmacher, Int. J. Mass Spectrom. Ion Processes, 83, 111 (1988); (d) H.-Fr. Grützmacher and G. Thielking, Org. Mass Spectrom. 23, 397 (1988).

14. It is difficult to exclude any $H / D$ exchange in the molecular ions of $1-d_{5}$ prior to the formation of the fragment ions $a$ because $a$ is an intermediate for most of the intense fragment ions in the $70 \mathrm{eV}$ El mass spectrum, but there are no indications for such an exchange. 